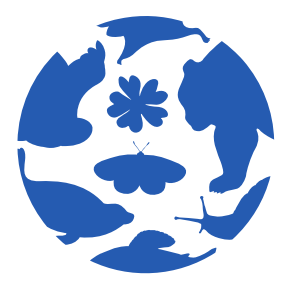

SUOMEN

LUONTO

PANEELI

\title{
KESKEISET KEINOT LUONTOKADON PYSÄYTTÄMISEKSI
}

Luontopaneelin viestit hallituksen puoliväliriiheen

Janne S. Kotiaho, Lassi Ahlvik, Christoffer Boström, Jaana Bäck, Irina Herzon, Jukka Jokimäki, Kirsi Pauliina Kallio, Liisa Kulmala, Aleksi Lehikoinen, Tiina M.

Nieminen, Elina Oksanen, Minna Pappila, Juha Pöyry, Heli Saarikoski, Aki Sinkkonen, Ilari Sääksjärvi ja Tarmo Ketola

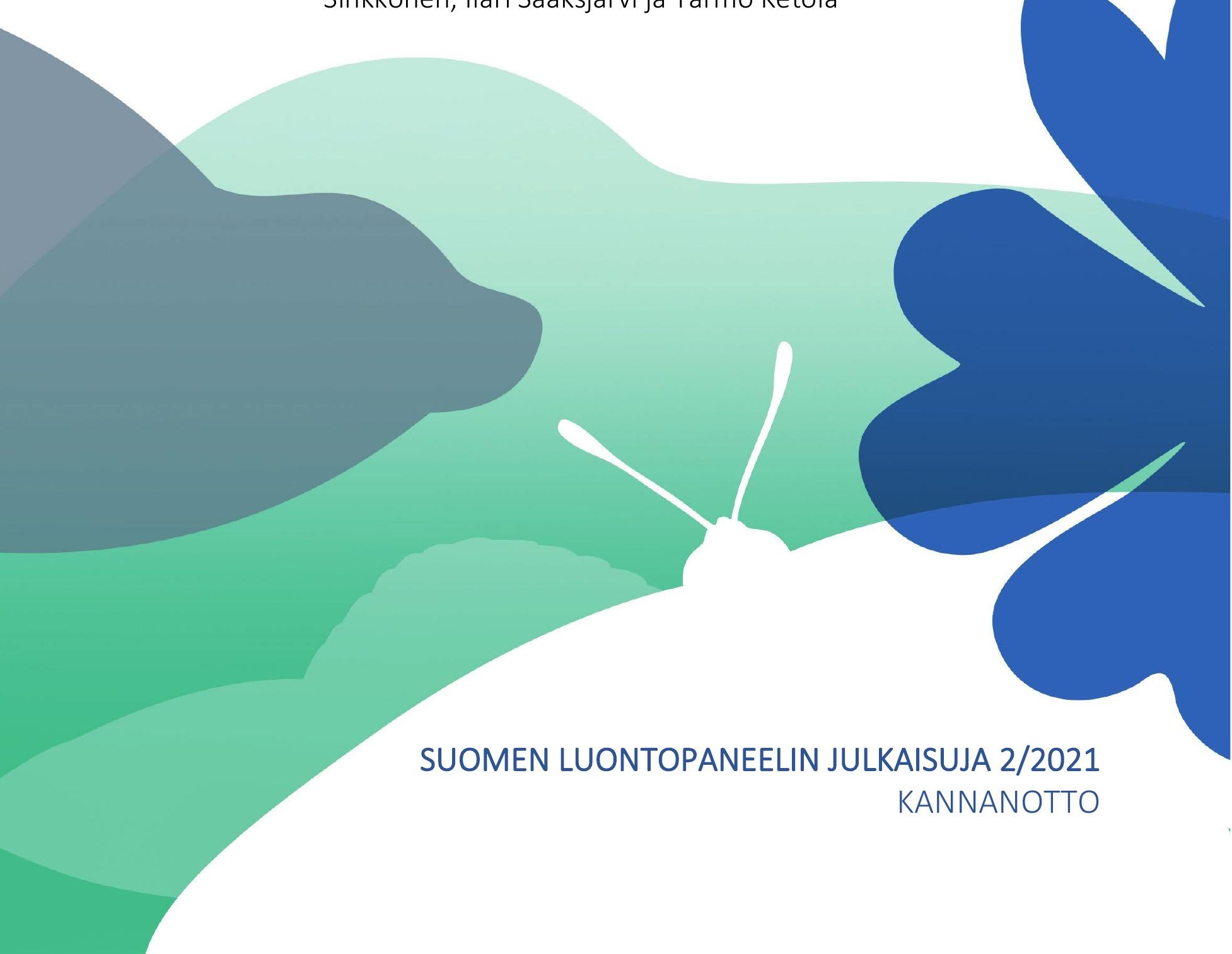




\section{Johdanto}

Sanna Marinin hallitus on sitoutunut luonnon monimuotoisuuden tilan parantamiseen ja luontokadon pysäyttämiseen ${ }^{1}$. Lupaus on äärimmäisen tärkeä. Luonnon ekosysteemien heikennys uhkaa elintärkeiden ekosysteemipalveluiden tuotantoa sekä ihmisten terveyttä, hyvinvointia ja turvallisuutta. Maailman talousfoorumi on nostanut luontokadon viiden vakavimman ihmiskuntaa uhkaavan riskin joukkoon². Myös Suomen luontotyyppien ja lajiston uhanalaisuustilanne on hälyttävää-5. Hallituksen kehysriihessä päätetään hallitusohjelman toteuttamisesta ja lunastetaan vuoden 2019 eduskuntavaalien lupaukset luonto- ja ilmastotoimista. Myös EU:n uusi biodiversiteettistrategia velvoittaa Suomea panostamaan luonnonsuojeluun entistä enemmän ${ }^{6}$.

\section{Kasvatetaan luonnonsuojelun määrärahoja nopeasti mutta pitkäjänteisesti}

Suomen Luontopaneeli katsoo, että nykyinen luonnonsuojelun rahoituksen taso on ehdoton minimitaso. Vaikka rahoitus niukasti kattaa tämänhetkisten Helmi- ja METSO-ohjelmien tavoitteet ${ }^{7,8}$, ohjelmien pintaalatavoitteet ja rahoitus ovat riittämättömiä luontokadon pysäyttämiseen. Yksi kustannustehokas tapa lisätä Iuonnonsuojelun pinta-alaa on suojella valtionmaiden alueita. Valtionmaita on myös Etelä-Suomessa Kokkolalisalmi linjan eteläpuolella useita satoja tuhansia hehtaareja, ja METSO-alueella valtion mailla sijaitsee edelleen runsaasti suojelemattomia kohteita, joilla on keskimääräisiä yksityismaiden METSO-alueita paremmat suojeluarvot ${ }^{8}$. Valtionmaiden suojelupinta-alan merkittävän kasvattamisen lisäksi hallituksen tulee varmistaa pitkäjänteinen luonnonsuojelun määrärahojen kasvattaminen, jotta luontokato eli luonnon ekosysteemien heikentyminen saadaan pysäytettyä.

Luontomatkailu on aluetaloudellisesti merkittävä tulon ja työllisyyden lähde ${ }^{9}$. Koronavuosi on tuonut esiin luontokohteiden merkityksen, mutta myös niiden rakenteiden huonon tilan ja luontokohteiden epätasaarvoisen saavutettavuuden eri kansalaisryhmille. Epätasa-arvoisuuden korjaamiseksi ja luonnon kulumisen ehkäisemiseksi kansallispuistojen ja suojelualueiden määrää on lisättävä ja retkeilyinfrastruktuureja parannettava. Tämä vaatii Metsähallituksen Luontopalveluiden toimintaedellytysten pitkäaikaisen turvaamisen siten, että korjausvelka ${ }^{10}$ saadaan katettua, uudet infrastruktuuri-investoinnit toteutettua täysimääräisesti ja investointien perusylläpito ja huolto suoritettua.

\section{Sitoudutaan luonnon kokonaisheikentymättömyyteen}

Luontokadon hidastaminen siirtää luonnon monimuotoisuuden ja ekosysteemien romahduksen ajankohtaa kauemmas tulevaisuuteen, mutta ei estä niitä. Tästä syystä luontokadon pysäyttäminen edellyttää sitoutumista luonnon kokonaisheikentymättömyyteen, joka tarkoittaa, että ekosysteemien tilaa ei heikennetä nykyisestä. Kaikkien taloutta elvyttävien toimien, investointien ja tukien luontovaikutukset tulee arvioida sekä keskittyä vähiten haitallisiin toimiin. Erityisesti ympäristölle haitalliset tuet ${ }^{11}$ on nopeasti poistettava.

\section{Käynnistetään luontohaittojen ylikompensoinnin velvoittavuuden valmistelu}

Yhteiskuntia kehitettäessä kaikkia luontohaittoja ei pääsääntöisesti ole mahdollista välttää. Väistämättömien luontohaittojen hyvittäminen eli ekologinen kompensaatio on välttämätöntä, jotta luontokato saadaan pysäytettyä ja voimme saavuttaa luonnon kokonaisheikentymättömyyden ${ }^{12}$. Velvoittamalla toiminnanharjoittajat haittojen ylikompensointiin luonnon tilaa voidaan jopa parantaa. Velvoitteen tulee koskea kaiken kokoisia toimia kaikilla sektoreilla. Suurilla hankkeilla on mittavat paikalliset haitat, mutta hankkeita on suhteellisen vähän. Pienimuotoiset toimet kuten esimerkiksi mökin rakentaminen tai pieni avohakkuu eivät aiheuta laajaa luontohaittaa, mutta kun niitä on paljon, ne voivat yhdessä aiheuttaa isoja hankkeita suuremman kokonaishaitan.

Luontopaneeli katsoo luontokadon pysäyttämisen olevan niin suuri haaste, että sen ratkaiseminen vaatii ylihallituskautista pitkäjänteistä ja suunnitelmallista työtä. Sen vuoksi hallituksen tulisi asettaa parlamen- 
taarinen monialainen komitea valmistelemaan luontohaittojen ylikompensoinnin velvoittavuutta ja käyttöönottoa. Kaikkien haittojen hyvittäminen on ainoa tiedossa oleva keino, jolla luontokato saadaan pysäytettyä ja voimme päästä kohti kokonaisheikentymätöntä tai jopa paranevaa luonnon tilaa.

\section{Tuetaan monimuotoisuutta ja työllisyyttä samanaikaisesti}

Luonnon monimuotoisuuden tilan parantaminen ja koronasta kärsineen talouden elvytys on mahdollista samanaikaisesti hyvällä suunnittelulla. Luontopaneeli raportoi aiemmin tänä vuonna, että erityisesti panostamalla suojelualueiden laajentamiseen, saavutettavuuteen ja matkailuun, kosteikkojen ennallistamiseen ja hoitoon, soiden suojeluun ja ennallistamiseen sekä vesistöjen vaellusesteiden purkuun voidaan tukea samanaikaisesti sekä luonnon monimuotoisuutta että aluetaloutta ja työllisyyttä12. Esimerkiksi turpeennostoalueiden ja erityisesti ravinteikkaiden, ojitettujen soiden ennallistaminen tuo ilmastohyötyjä, vahvistaa suoluonnon monimuotoisuutta ja mahdollistaa uutta kestävää työtä turveyrittäjille. Sen sijaan erityisesti metsien käyttöä lisäävät hankkeet kuten biojalostamot ovat haitallisia sekä ilmastolle että metsäluonnon monimuotoisuudelle ${ }^{12}$.

\section{Lisätään ympäristökasvatusta}

Suomalaisten kulutus on kestämätöntä ja vuosittain kulutamme oman osamme maapallon uusiutuvista luonnonvaroista jo huhtikuussa. Jokainen luonnonvarojen kulutukseen liittyvä päätös on merkityksellinen ja vie meitä joko kohti kestävää tulevaisuutta tai poispäin siitä. Suomalaisten globaalia ekologista jalajälkeä tulee leikata keskimäärin 70 prosenttia pysyäksemme luonnon kantokyvyn rajoissa.

Luonnon monimuotoisuuden heikkeneminen tapahtuu ilman, että suuri osa suomalaisista ymmärtää näin käyvän. Luontokadon ja ilmastonmuutoksen yhteenkietoutuvista syistä, seurauksista ja torjunnan keinoista on tuotettava helposti ymmärrettävää tietoa, jota kansalaiset voivat omaksua ja käyttää. Tämän tiedon tuottamista ja välittämistä kaikille ikäluokille tulee tukea. Hallituksen tulee voimakkaammin kannustaa oppilaitoksia panostamaan ympäristökasvatukseen sekä kaikille avoimessa jatkuvassa oppimisessa että opettajien täydennyskoulutuksessa. Lisäksi tukea tulee suunnata ympäristökasvatusta tekeville yhdistyksille, luonto- ja tiedekeskuksille sekä museoille.

\section{Toteutetaan vihreä siirtymä vähähiiliseen yhteiskuntaan}

Vihreä siirtymä pitää toteuttaa päämäärätietoisesti. Suomen tilanteessa tämä tarkoittaa muun muassa turpeen energiakäytöstä luopumista ja muidenkin käyttömuotojen määrätietoista vähentämistä. Tämän tavoitteen saavuttamiseksi on tärkeää, että tuetaan turpeesta luopuvia yrittäjiä eikä turpeen käytön lisäämiseksi esitettyjä tukia, investointeja ja mekanismeja ${ }^{14}$ toteuteta. Energiaturpeen käytöstä luovuttaessa tulee välttää sen korvaamista metsähakkeella, koska tämä johtaisi metsien lisääntyvään käyttöön, uhaten metsäluonnon monimuotoisuutta ja tehden osaltaan tyhjäksi muita ilmastotoimia ${ }^{12,15}$. Turpeen energiakäyttöä tuleekin korvata esimerkiksi rakennusten energiatehokkuuden parantamisella, lämpöpumppuinvestoinneilla ja syvälämpöhankkeilla, kestävästi tuotetulla biokaasulla, ja tuuli- ja aurinkovoimalla ${ }^{12,15}$. Metsien hiilinieluja ja -varastojen pysyvyyttä vahvistavien kannustimien luominen edistäisi yhtä aikaa puun tuotannon kokonaisvaltaista kestävyyttä, ilmastonmuutoksen torjuntaa ja luonnon monimuotoisuutta. 


\section{LÄHTEET}

1 Valtioneuvosto. 2019. Osallistava ja osaava Suomi - sosiaalisesti, taloudellisesti ja ekologisesti kestävä yhteiskunta. Pääministeri Sanna Marinin hallituksen ohjelma 2019. https://valtioneuvosto.fi/marininhallitus/hallitusohjelma.

2 World Economic Forum. 2021. The Global Risk Report. https://www.weforum.org/reports/the-global-risksreport-2021.

3 Hyvärinen, E., Juslén, A., Kemppainen, E., Uddström, A. \& Liukko, U.-M. (toim.) 2019. Suomen lajien uhanalaisuus - Punainen kirja 2019. Ympäristöministeriö \& Suomen ympäristökeskus. Helsinki.

4 Kontula, T. \& Raunio A. (toim.) 2018. Suomen luontotyyppien uhanalaisuus 2018. Luontotyyppien punainen kirja - Osa 1: Tulokset ja arvioinnin perusteet. Suomen ympäristökeskus ja ympäristöministeriö, Helsinki. Suomen ympäristö 5/2018. 388 s.

5 Auvinen, A.-P., Kemppainen, E., Jäppinen, J.-P., Heliölä, J., Holmala, K., Jantunen, J., Koljonen, M.-L., Kolström, T., Lumiaro, R., Punttila, P., Venesjärvi, R., Virkkala R. \& Ahlroth P. 2020. Suomen biodiversiteettistrategian ja toimintaohjelman 2012-2020 toteutuksen ja vaikutusten arviointi. Valtioneuvoston selvitys- ja tutkimustoiminnan julkaisusarja 2020:36.

6 EU. 2020. Biodiversity strategy for 2030. Bringing Nature back into our lives.

7 Ympäristöministeriö. 2020. Helmi-elinympäristöohjelma vahvistaa luonnon monimuotoisuutta. https://ym.fi/helmi.

8 Hohti, J., Halme, P., Hjelt, M., Horne, P., Huovari, J., Lensu, A., Mäkilä, K., Mönkkönen, M., Sajeva, M. \& Kotiaho J. S. 2019. Kymmenen vuotta METSOa - Väliarviointi Etelä-Suomen metsien monimuotoisuuden toimintaohjelman ensimmäisestä vuosikymmenestä. Ympäristöministeriön julkaisuja 2019:4.

9 Matkailutilinpito. 2020. Matkailun talous- ja työllisyysvaikutukset 2017-2018. Visit Finlandin tutkimuksia.

10 Metsähallitus. 2019. Metsähallituksen Luontopalvelujen korjausvelkaselvitys 2018. Metsähallitus Luontopalvelut.

11 Hyyrynen, M. 2013. Ympäristön kannalta haitalliset tuet. Ympäristöministeriön raportteja 13.

12 Ahlvik, L., Boström, C., Bäck, J., Herzon, I., Jokimäki, J., Kallio, K. P., Ketola, T., Kulmala, L., Lehikoinen, A., Nieminen, T. M., Oksanen, E., Pappila, M., Pöyry, J., Saarikoski, H., Sinkkonen, A., Sääksjärvi, I. \& Kotiaho, J. S. 2021. Luonnon monimuotoisuus ja vihreä elvytys. Suomen Luontopaneeli. Suomen Luontopaneelin julkaisuja $1 / 2021$.

13 Global Footprint Network. 2021. Earth Overshoot Day. Verkossa: https://www.overshootday.org/aboutearth-overshoot-day/.

14 Turvetyöryhmä. 2021. Työpaperi. 30.3.2021. Työ- ja elinkeinoministeriö.

15 Soimakallio, S., Sankelo, P., Kopsakangas-Savolainen, M., Sederholm, C., Auvinen, K., Heinonen, T., Johansson, A., Judl, J., Karhinen, S., Lehtoranta, S., Räsänen, S. \& Savolainen, H. 2020. Turpeen rooli ja sen käytöstä luopumisen vaikutukset Suomessa. Sitra, tekninen raportti. 


\section{(c) (1)}

Suomen Luontopaneelin julkaisuja 2/2021

Kannanotto

\section{Keskeiset keinot luontokadon pysäyttämiseksi}

Tekijät:

Janne S. Kotiaho (Jyväskylä yliopisto, janne.kotiaho@jyu.fi), Lassi Ahlvik (Helsingin yliopisto), Christoffer Boström (Åbo Akademi), Jaana Bäck (Helsingin yliopisto), Irina Herzon (Helsingin yliopisto), Jukka Jokimäki (Arktinen keskus), Kirsi Pauliina Kallio (Tampereen yliopisto), Liisa Kulmala (Ilmatieteen laitos), Aleksi Lehikoinen (Luonnontieteellinen keskusmuseo Luomus), Tiina M. Nieminen (Luonnonvarakeskus), Elina Oksanen (Itä-Suomen yliopisto), Minna Pappila (Turun yliopisto), Juha Pöyry (Suomen ympäristökeskus), Heli Saarikoski (Suomen ympäristökeskus), Aki Sinkkonen (Luonnonvarakeskus), Ilari Sääksjärvi (Turun yliopisto) ja Tarmo Ketola (Jyväskylän yliopisto).

Toimitussihteeri: Sanna Autere

ISSN: 2737-0062

DOI: https://doi.org/10.17011/jyx/SLJ/2021/2

Viittausohje:

Kotiaho, J. S., Ahlvik, L., Boström, C., Bäck, J., Herzon, I., Jokimäki, J., Kallio, K. P., Kulmala, L., Lehikoinen, A., Nieminen, T. M., Oksanen, E., Pappila, M., Pöyry, J., Saarikoski, H., Sinkkonen, A., Sääksjärvi, I. \& Ketola, T. 2021. Keskeiset keinot luontokadon pysäyttämiseksi. Luontopaneelin viestit hallituksen puoliväliriiheen. Suomen Luontopaneelin julkaisuja 2/2021.

Suomen Luontopaneeli on riippumaton asiantuntijaelin, joka tukee luontopolitiikan suunnittelua ja päätöksentekoa. Luontopaneelin kannanotot ja raportit perustuvat tieteelliseen näyttöön ja monialaiseen asiantuntemukseen.

www.luontopaneeli.fi

@luontopaneeli 